\title{
Tapering and Discontinuation of Thrombopoietin Receptor Agonist Therapy in Patients with Immune Thrombocytopenia: Results from a Modified Delphi Panel
}

\author{
Nichola Cooper ${ }^{a}$ Quentin A. Hill ${ }^{b}$ John Grainger ${ }^{c}$ John-Paul Westwood ${ }^{d}$ \\ Charlotte Bradbury ${ }^{\mathrm{e}}$ Drew Provan ${ }^{f}$ Jecko Thachilg Nicholas Ramscar ${ }^{\mathrm{h}}$ \\ Anuja Royi \\ aDepartment of Haematology, Hammersmith Hospital, London, UK; bepartment of Haematology, The Leeds \\ Teaching Hospital, Leeds, UK; 'Department of Pediatric Haematology, Royal Manchester Children's Hospital, \\ Manchester, UK; ${ }^{d}$ Department of Haematology, University College London Hospital, London, UK; ${ }^{\mathrm{e} B r i s t o l}$ \\ Haematology and Oncology Centre, University of Bristol, Bristol, UK; fDepartment of Haematology, Barts and the \\ London School of Medicine, London, UK; ${ }^{9}$ Department of Haematology, Central Manchester University Hospital,

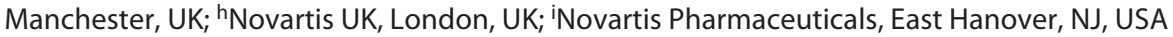

\section{Keywords}

Eltrombopag $\cdot$ Immune thrombocytopenia $\cdot$ Romiplostim . Thrombopoietin receptor agonists · Treatment discontinuation

\footnotetext{
Abstract

Background: Recent evidence suggests that in patients with immune thrombocytopenia (ITP) with a stable response on thrombopoietin receptor agonists, treatment may be tapered and/or discontinued. Objectives: The objective of this study was to provide a guide for tapering and discontinuation of TPO-RA therapy in patients with ITP, based on hematologist survey results, existing evidence, and expert consensus. Patients/Methods: UK hematologists completed a survey to characterize self-reported practice patterns related to TPO-RA tapering and discontinuation in patients with ITP. Using a modified Delphi panel approach, ITP experts developed consensus statements regarding the use of TPO-RA tapering and discontinuation. Results: Survey respondents es-
}

timated that $30-34 \%$ of their patients were suitable for tapering or discontinuation and that $29-35 \%$ of these patients required treatment re-initiation after an average treatmentfree interval of 86-106 days. No clear predictors of patient suitability or response to tapering or discontinuation were identified. The ITP expert consensus was that approximately $30 \%$ of patients are eligible for tapering and discontinuation, which may be considered after 6-12 months for patients demonstrating an adequate treatment response (platelet count $>50,000 / \mu \mathrm{L}$ at $\geq 75 \%$ of assessments in the preceding 6 months). Treatment re-initiation may be considered if the platelet count decreases or if the patient becomes symptomatic. Individual differences need to be taken into account when considering TPO-RA tapering or discontinuation. Conclusions: Tapering and discontinuation of TPO-RA therapy may be considered for certain patients with ITP. Further study is needed to better predict patients likely to achieve sustained off-treatment responses after tapering and discontinuation.

(c) 2021 The Author(s)

Published by S. Karger AG, Basel karger@karger.com www.karger.com/aha

Karger $\stackrel{\text { ' }}{5}$

BOPEN ACCESS
(C) 2021 The Author(s)

Published by S. Karger AG, Basel

This is an Open Access article licensed under the Creative Commons Attribution-NonCommercial-4.0 International License (CC BY-NC) (http://www.karger.com/Services/OpenAccessLicense), applicable to the online version of the article only. Usage and distribution for commercial purposes requires written permission.
Correspondence to:

Nichola Cooper, n.cooper@imperial.ac.uk 


\section{Introduction}

Immune thrombocytopenia (ITP) is an autoimmune disorder resulting in reduced platelet production and increased platelet destruction [1]. Platelets and their precursors, megakaryocytes, are targeted by autoantibodies, leading to an increased risk of bleeding [2]. Diagnosis is based on a platelet count $<100,000 / \mu \mathrm{L}$, but platelet counts between 20,000 and $100,000 / \mu \mathrm{L}$ are associated with a lower risk of major bleeding events than are values $<20,000$ / $\mu \mathrm{L}[1,3]$. Treatment is typically reserved for patients with platelet counts $<20,000-30,000 / \mu \mathrm{L}$, active bleeding, or a high risk of bleeding (e.g., patients undergoing surgery) $[1,3]$.

Thrombopoietin receptor agonists (TPO-RAs) induce proliferation and differentiation of megakaryocytes, thereby increasing platelet production [4]. Eltrombopag and romiplostim have been shown to improve platelet count and prevent major bleeding events in $80-90 \%$ of patients with ITP $[5,6]$ and may improve quality of life [7]. Response rates of $65-88 \%$ have been reported in long-term follow-up studies [8-10]. TPO-RAs are generally well tolerated by patients, even with long-term treatment [11]. Adverse events of romiplostim and eltrombopag reported in phase 3 trials were similar and generally mild; serious adverse events most frequently consisted of bleeding events in patients with low platelet counts $[8,12,13]$. Eltrombopag and romiplostim are approved by the European Medicines Agency and the US Food and Drug Administration for patients aged 1 year and above with primary ITP who are refractory to other treatments such as corticosteroids and immunoglobulins $[14,15]$.

The goal of TPO-RA therapy is not to normalize the platelet count but to elevate it to a level that minimizes the risk of bleeding, that is, a platelet count of 50,000-150,000/ $\mu \mathrm{L}[14,15]$. For patients who can subsequently maintain a platelet count in the normal range without treatment, these agents will be titrated down. If, however, a platelet count $>50,000 / \mu \mathrm{L}$ is considered safe, an additional question is whether some patients maintaining a platelet count of $50,000-150,000 / \mu \mathrm{L}$ on treatment can taper and stop their TPO-RA while maintaining their platelet level. Hematologists should evaluate their patients treated with TPO-RAs periodically and assess whether to continue TPO-RA treatment $[14,15]$.

Many patients require continuous TPO-RA therapy to maintain adequate platelet levels [16]. However, some patients may have sustained off-treatment responses after discontinuation of TPO-RA therapy [10, 17-24]. Various

Therapy Discontinuation in Immune

Thrombocytopenia approaches to tapering and discontinuation of TPO-RA therapy have been used, and there is currently no consensus regarding the optimal approach $[17,21]$. In addition, several questions remain regarding the identification of suitable patients for tapering and discontinuation, the expected duration of response after discontinuation, and methods for re-initiating therapy. Previous studies did not find any clinical or treatment characteristics that may predict a lasting response after treatment discontinuation $[17,19,21,22]$. Červinek et al. [17] found higher rates of sustained off-treatment responses in patients requiring low TPO-RA doses, whereas no responses were seen in patients who required higher doses. Another study suggested that absolute immature platelet fractions may be a potential predictor of successful treatment termination [22]. However, sample sizes in these 2 studies were small. Finally, the definition of treatment response varied between studies, even though international definitions exist [25]. In the absence of a consolidated knowledge base, a practice survey was administered to UK hematologists and a modified Delphi panel process among ITP experts was hosted to consider consensus recommendations related to tapering and discontinuation of TPO-RA therapy in patients with ITP.

\section{Methods}

Survey of UK Hematology Practices

For the ITP expert consensus panel to consider the self-reported perspectives and experiences of practicing hematologists, a survey was designed and conducted. Survey methods considered appropriate best practices to optimize relevance and responsiveness for physician surveys [26, 27].

Hematologists and hematologic oncologists in practice for at least 3 years in the UK who had evidence of experience treating patients with TPO-RAs (based on prescribing practices) were included. A survey panel methodology was used to invite eligible hematologists to participate in a survey regarding their perceptions of and personal experience with tapering and discontinuation of TPO-RAs in patients with ITP (online suppl. Appendix 1; see www. karger.com/doi/10.1159/000510676 for all online suppl. material). Best practices in survey design were applied to avoid or minimize potential instrumentation bias or other sources of bias. A total of 495 hematologists were approached, with a target completion rate of $12 \%(n=60)$, based on feasibility and time (1 week) for response. Descriptive statistics and content analysis were used to analyze responses.

\section{ITP Expert Consensus Meeting}

A live meeting was convened to synthesize evidence and practices related to TPO-RA tapering, discontinuation, and re-initiation among UK-based experts in the management of ITP. The ITP experts completed a pre-meeting survey (online suppl. Appendix 2) to establish their perspectives and experience related to the over- 
all of TPO-RA tapering and discontinuation, identification of appropriate patients, expected outcomes after discontinuation, duration of off-treatment response, and unmet needs in supporting evidence that might prevent the development of recommendations.

In June 2017, seven ITP experts participated in a modified Delphi panel. This convenience sample of UK-based hematologists was put together for the panel using snowball referencing and was based on their expertise in the field and their experience with a larger number of patients with ITP. The meeting was supported by a structured technology-based platform to capture uninfluenced individual perspectives followed by a panel discussion where consensus among participants was sought. The online meeting platform enables anonymized collaboration through open data entry, surveying, and evaluations using ratings and rankings. The ITP experts also estimated the duration of TPO-RA discontinuation in their last 3 patients who had undergone TPO-RA tapering, discontinuation, and re-initiation of therapy. The meeting agenda included discussion regarding criteria for appropriate TPO-RA tapering and discontinuation as well as criteria for treatment re-initiation in patients who relapse after treatment discontinuation.

\section{Results}

\section{Survey of UK Hematology Practices}

The survey was completed by 49 of 495 hematologists (9.8\%). Respondents had been in practice for an average of 12 years. Most were based in academic or teaching hospitals (84\%), spending $86 \%$ of their time in direct patient care. Respondents reported managing an average of 47 patients with ITP over the past 6 months.

The number of respondents reporting experience with tapering and discontinuation of eltrombopag and romiplostim was 17 (35\%) and 23 (47\%), respectively. Survey respondents estimated that $30-34 \%$ of patients with ITP treated with TPO-RAs were suitable candidates for tapering or discontinuation. A stable platelet count was the most commonly cited reason for tapering and discontinuing treatment (58-76\%), followed by a lack of or reduced risk of bleeding (17-24\%; Table 1).

Survey respondents reported that $29-35 \%$ of their patients required re-initiation of treatment after discontinuing TPO-RA therapy. Treatment was re-initiated after a mean treatment-free interval of 86-106 days. The most commonly cited reason for treatment re-initiation was decreased platelet count (100\%) followed by clinical symptoms (67-75\%). The most common form of renewed treatment was TPO-RAs (Table 1). Hematologists reported that among their patients initially treated with eltrombopag, $44 \%$ received eltrombopag and $41 \%$ received romiplostim upon treatment re-initiation. Among those initially treated with romiplostim, $28 \%$ received el-
Table 1. Responses from 49 UK hematologists participating in the survey

\begin{tabular}{lll} 
Hematologist response, \% & $\begin{array}{l}\text { Eltrom- } \\
\text { bopag }\end{array}$ & $\begin{array}{l}\text { Romi- } \\
\text { plostim }\end{array}$ \\
\hline
\end{tabular}

Criteria used to define "well controlled" ITP for TPO-RA tapering and discontinuation

Stable platelet count $\quad 58 \quad 76$

Well-controlled symptoms or symptom-free $\quad 25 \quad 0$

$\begin{array}{lll}\text { Lack of or reduced risk of bleeding } & 17 & 24\end{array}$

Reasons for treatment re-initiation

$\begin{array}{lrr}\text { Platelet count } & 100 & 100\end{array}$

$\begin{array}{lll}\text { Clinical symptoms } & 67 & 75\end{array}$

Other

$20 \quad 0$

Type of therapy used at treatment re-initiation

$\begin{array}{lll}\text { Eltrombopag } & 44 & 28\end{array}$

Romiplostim $\quad 41 \quad 39$

$\begin{array}{lll}\text { Other pharmacologic treatment } & 11 & 7\end{array}$

Surgery $\quad 6 \quad 4$

Other nonpharmacologic regimen $\quad 2 \quad 1$

ITP, immune thrombocytopenia; TPO-RA, thrombopoietin receptor agonist.

trombopag and 39\% received romiplostim when treatment was re-initiated.

\section{Expert Consensus Meeting}

Among the ITP experts, pre-meeting questionnaire responses indicated a high level of agreement that tapering of TPO-RA therapy can be a rational approach to ITP treatment and that discontinuation may be warranted in clinically improved patients who feel well. During the group discussion, several potential benefits of TPO-RA tapering and discontinuation were identified, including the possibility of treatment-free remission and increased patient convenience (Fig. 1).

\section{ITP Expert Panel Opinion}

- Tapering and discontinuation of TPO-RA therapy may be considered for certain patients.

The ITP experts agreed that a tapering approach may be considered after 6-12 months of treatment for patients with an adequate treatment response who are less likely to encounter a high-risk bleeding scenario. An adequate treatment response was defined as stable platelet count $>50,000 / \mu \mathrm{L}$ in at least $75 \%$ of assessments in the preceding 6 months. Tapering should be done slowly. In patients with platelet levels $<30,000 / \mu \mathrm{L}$ after tapering or discontinuing TPO-RAs, hematologists may consider a watch- 
Fig. 1. Potential benefits of TPO-RA tapering and discontinuation (expert opinion). TPO-RA, thrombopoietin receptor agonist.

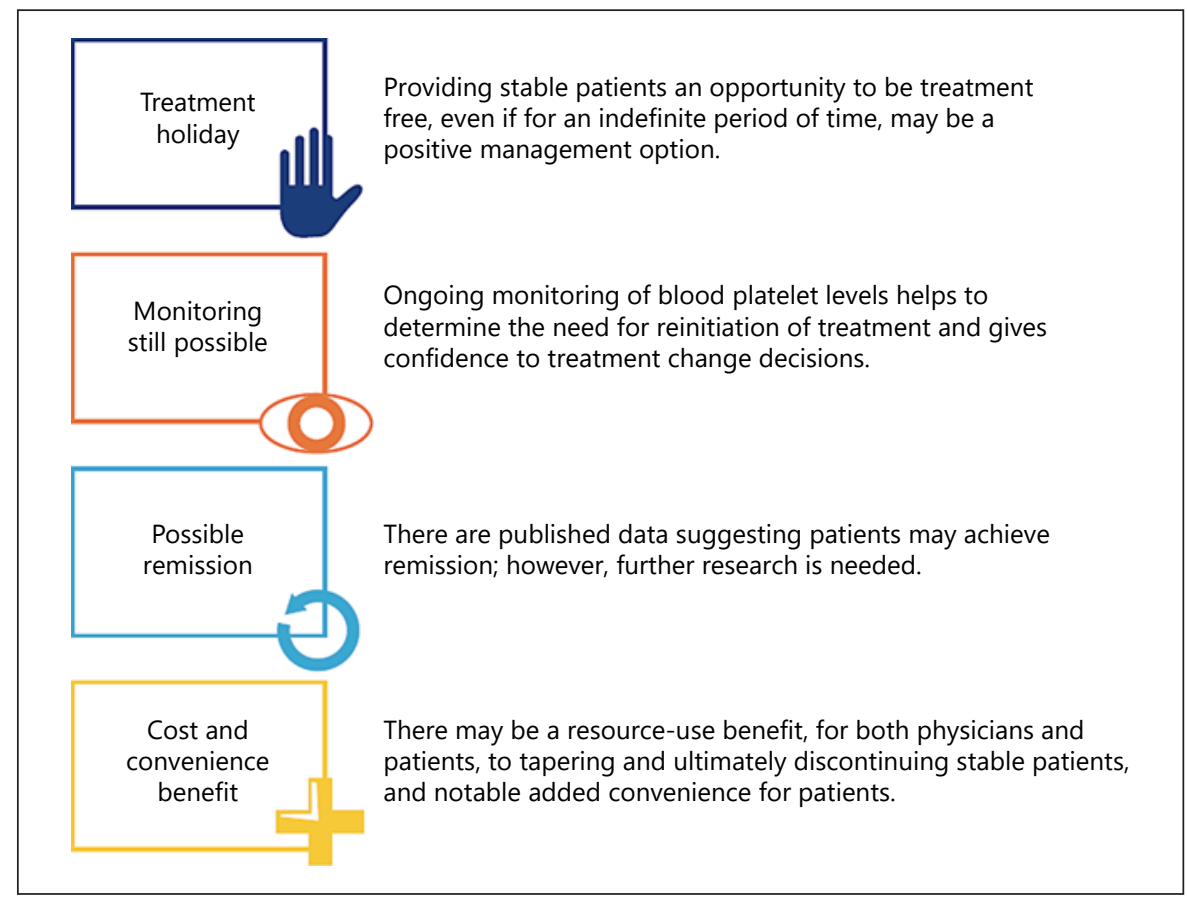

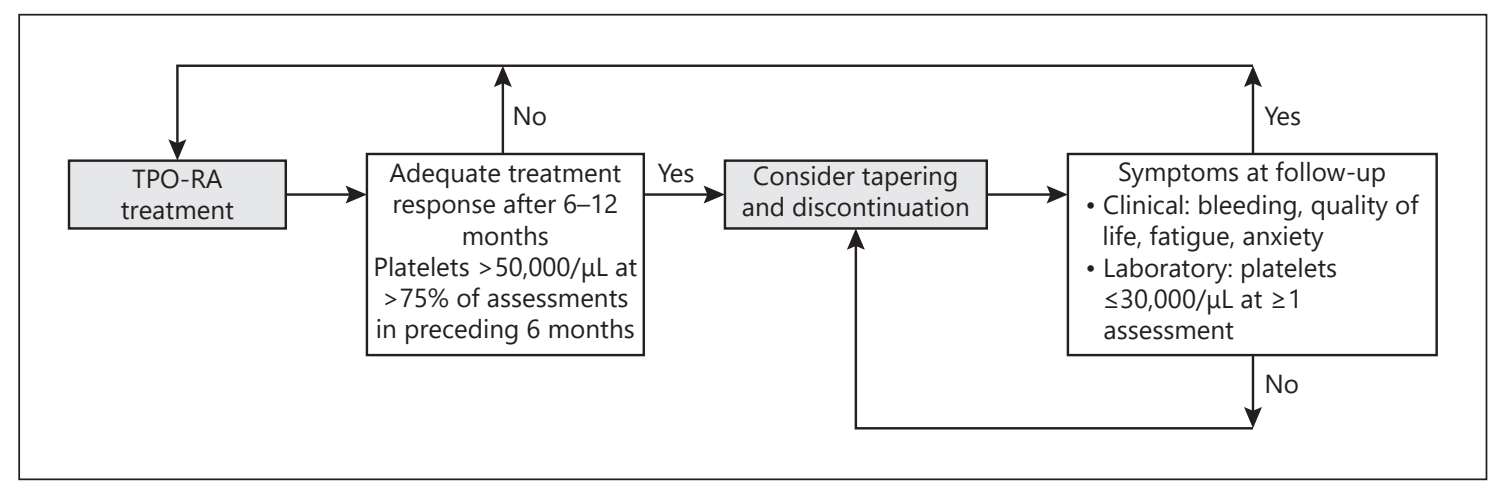

Fig. 2. TPO-RA tapering and discontinuation approach that can be considered for patients with primary ITP. ITP, immune thrombocytopenia; TPO-RA, thrombopoietin receptor agonist.

and-wait approach, maintaining the same dose level, to see if any bleeding occurs and check their platelet levels after a few weeks to account for natural fluctuations that occur, especially in patients treated with romiplostim. A flow chart of the suggested tapering and discontinuation approach is shown in Figure 2. The ITP experts also stressed that individual differences (e.g., asymptomatic chronically low platelet counts), patient preferences, and the impact of frequent testing on patients need to be taken into account when considering tapering and discontinuation of TPO-RA therapy, and benefits and risks should be considered carefully.

Therapy Discontinuation in Immune Thrombocytopenia
The ITP experts agreed that tapering or discontinuation may need to be reconsidered if the platelet count decreases to $30,000 / \mu \mathrm{L}$ or lower. Stopping tapering or restarting treatment may also need to be considered if patients experience bleeding and/or persistently worse quality of life due to anxiety, fatigue, or other factors related to ITP that could be alleviated by TPO-RA treatment.

\section{ITP Expert Panel Opinion}

- Tapering may be considered after 6-12 months for patients with an adequate treatment response. 
Fig. 3. Patient characteristics that may be potential indicators of remission or relapse during tapering or discontinuation of TPO-RAs, based on expert opinion. ITP, immune thrombocytopenia; TPO-RA, thrombopoietin receptor agonist.

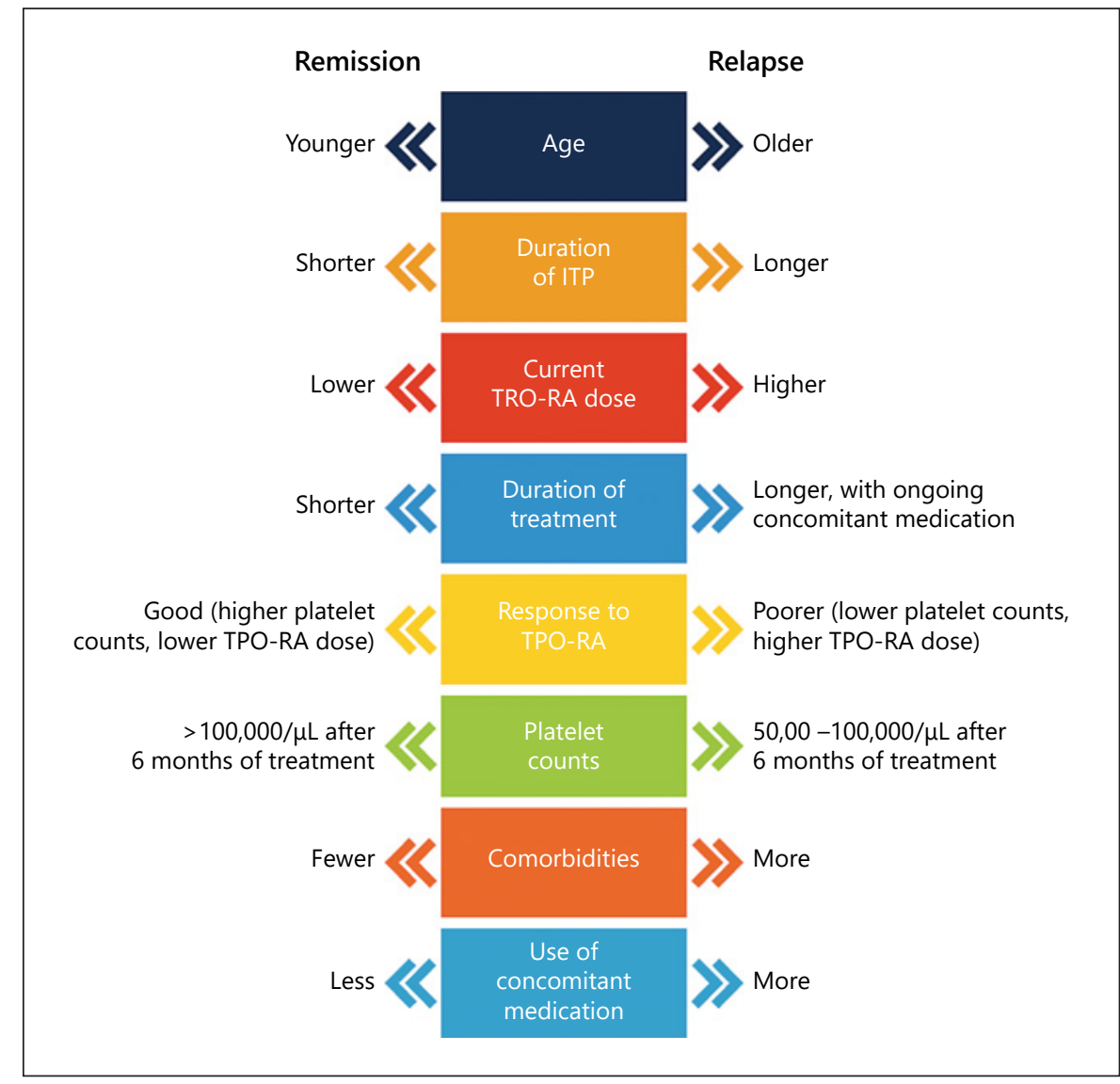

- An adequate treatment response was defined as stable platelet count $>50,000 / \mu \mathrm{L}$ at $\geq 75 \%$ of assessments in the preceding 6 months.

- Tapering and discontinuation may need to be reconsidered if the platelet count decreases to $\leq 30,000 / \mu \mathrm{L}$ or if the patient experiences bleeding, persistently worse quality of life, anxiety, or fatigue associated with ITP that might be alleviated by resuming TPO-RA therapy.

- Individual differences and patient preferences should be taken into account.

According to the ITP experts, identifying suitable patients for tapering and discontinuation was one of the key challenges. At this time, it is not possible to predict with confidence which patients will achieve off-treatment responses, and how long treatment response will last. It was agreed that currently there are no clear predictive factors to help identify patients suitable for tapering. However, the ITP experts identified several factors that they would consider when deciding whether to taper or discontinue therapy (Fig. 3). These factors include age, disease duration, response, duration of treatment, cur- rent TPO-RA dose, platelet count, comorbidities, and concurrent use of other medication for ITP. Tapering and discontinuation may be considered especially in patients without bleeding events who are on a low dose of TPO-RAs.

Notably, the ITP experts also identified 2 primary factors that would make a tapering or discontinuation approach less appropriate: a history of severe or life-threatening bleeding and no effective rapid rescue therapy. Tapering or discontinuation may be less appropriate in case of a history of large fluctuations in platelet count, the presence of comorbidities that increase bleeding risk, concomitant use of anticoagulant or antiplatelet medications, and a history of rapid relapse after dose reduction. Continuing on a minimum dose or applying a step-wise titration over a longer period may be an appropriate tapering strategy for patients with fluctuating responses to treatment or in patients in whom responses to dose reductions need to be monitored relatively frequently. The ITP experts believe this will reduce the risk of withdrawal effects and maintain stability for the patient. 


\section{ITP Expert Panel Opinion}

- There are no clear predictive factors to help identify patients who may be suitable for tapering and discontinuation.

- When deciding whether to taper or discontinue TPORA therapy, factors related to the patient (age), disease duration, and treatment (prior response to TPO-RA) may need to be taken into account.

- Situations in which tapering may not be appropriate include patients with a history of severe or life-threatening bleeding and the lack of effective rapid rescue therapy.

According to the ITP experts, the average duration of TPO-RA discontinuation, based on their last 3 patients, was $2-3$ months. The longest reported treatment-free interval estimate was $4-5$ years. The ITP experts reported that $34.7 \%$ of patients who discontinued eltrombopag and $29.1 \%$ of patients who discontinued romiplostim required TPO-RA re-initiation, pharmacologic therapy, or surgery. The most common reasons to re-initiate therapy were a decrease in platelet count and the presence of symptoms, such as clinically significant bleeding. The ITP experts also agreed that if the platelet count decreases or the patient develops clinically relevant symptoms, the treating hematologist, in conjunction with the patient, may need to re-evaluate tapering and, if necessary, revert to the previous TPO-RA dose.

\section{ITP Expert Panel Opinion}

- For patients who discontinue TPO-RA therapy, re-initiation of treatment may need to be considered if the platelet count decreases or the patient develops clinically relevant symptoms.

\section{Discussion}

In patients with ITP who show an adequate response to TPO-RA treatment, there is some evidence to suggest that TPO-RA therapy may be tapered with the intent of discontinuation, with monitoring to re-initiate therapy when platelet levels decrease beyond a certain threshold $[17,20,28]$. The results from our survey suggest that at least a subset of UK hematologists have applied such a tapering and discontinuation strategy in their patients with ITP (35 and $47 \%$ of those treated with eltrombopag or romiplostim, respectively). Despite the absence of broader guidelines, there appears to be a willingness among the responding physicians to try a tapering and discontinuation strategy in suitable patients. Our find-

Therapy Discontinuation in Immune

Thrombocytopenia ings align with a previous review of practice among UK hematologists, which showed that most hematologists would taper down TPO-RAs in patients with stable platelet counts, although the definition of a stable platelet count varied among respondents [29].

In the absence of published guidelines, our panel of ITP experts achieved consensus regarding initial practice strategies related to potential tapering and discontinuation of TPO-RA therapy. The consensus was that tapering and discontinuation may be considered after 6-12 months of TPO-RA treatment for patients with an adequate treatment response (defined as a platelet count $>50,000 / \mu \mathrm{L}$ in at least $75 \%$ of assessments in the preceding 6 months, i.e., a stable platelet count). Our findings are consistent with published reports on TPO-RA discontinuation and support this approach for select patients with ITP.

Potential benefits of intermittent versus continuous therapy include improved convenience that could enhance patient compliance and treatment satisfaction since patients may prefer treatments that can be given intermittently or even discontinued [21]. Long-term use of TPO-RAs is associated with tolerability issues, which have not yet been fully elucidated. For example, the significance of increased bone marrow fibrosis remains uncertain [30]. Furthermore, discontinuing TPO-RA therapy in patients with stable disease may reduce treatment costs, use of resources, and patient and physician burden.

Numerous approaches to tapering and discontinuation with varying results have been reported $[10,17,19$, 20, 22, 23, 28]. Most were small, retrospective studies based on case series from a single centre. Platelet counts achieved with TPO-RAs before tapering or discontinuation ranged between 50,000 and $150,000 / \mu \mathrm{L}$ in some studies $[17,22]$ but were much higher $(>850,000 / \mu \mathrm{L}$ in individual patients) in most studies [10, 17, 19-23]. In clinical trials, more than $80 \%$ of patients with ITP respond to eltrombopag (response defined as platelet count $\geq 50,000 / \mu \mathrm{L})$ [5], and response was maintained with long-term treatment (31 weeks) in $>50 \%$ of cases [6]. One prospective study has been reported in which romiplostim was systematically tapered in patients with ITP who achieved platelet counts $\geq 50,000 / \mu \mathrm{L}$ within 1 year [31]. Almost one-third of patients $(n=24 / 75)$ maintained stable platelet counts $\geq 50,000 / \mu \mathrm{L}$ for $>24$ weeks. In the REPEAT study, 32 patients treated with eltrombopag $\leq 75 \mathrm{mg} /$ day for $\geq 4$ months and platelet count $>50,000 / \mu \mathrm{L}$ were tapered at 4 -week intervals in $10-20 \%$ dose increments over 2 years [28]. This study showed that intermittent short-term eltrombopag may be an ef- 
fective and safe alternative in patients with ITP who do not require daily therapy but who do require intermittent use.

Our panel participants reported their patients to have treatment-free periods of approximately 2-3 months between discontinuing TPO-RA therapy and TPO-RA reinitiation, which was required in one-third of these patients. In previous studies, duration of TPO-RA treatment before tapering or discontinuation typically ranged between 6 and 12 months (range, 0.07-70 months) [10, $17,19,20,22,23]$. In studies with a median follow-up of 6-12 months or more, sustained off-treatment response after discontinuation of eltrombopag or romiplostim was seen in $5-30 \%$ of patients $[10,18-23]$. Relapses were observed in $8-47 \%$ of patients after discontinuation $[19,20$, 22 ]. Few patients required rescue therapy during followup $[10,17-22]$. For example, in a Spanish registry study, 11 of 12 patients responded to re-treatment with TPORAs [19]. Real-world data showed similar results: 53$64 \%$ of US patients with ITP discontinued eltrombopag, mostly within 6 months after treatment initiation [24]. Approximately $25 \%$ of these patients restarted eltrombopag; of those who did not, $16.7-55.6 \%$ did not receive any other treatment for ITP.

In the survey, hematologists reported a decrease in platelet count to be the primary driver of their decision to re-initiate treatment after a TPO-RA treatment-free period. These reports suggest that physicians do not always wait until clinical symptoms manifest and highlight the importance of continued monitoring of laboratory values after TPO-RA discontinuation. Our findings are in line with a previous review of practice among UK hematologists, which showed that most hematologists would taper down TPO-RAs in patients with stable platelet counts, although the threshold platelet count that would trigger a treatment taper ranged from 50,000 to $150,000 / \mu \mathrm{L}$ [29].

The ITP expert panel reinforced the absence of explicit, proven methods to predict patient suitability for a TPO-RA tapering and discontinuation strategy. Available evidence suggests that patient age, disease duration, and treatment history do not reliably predict sustained off-treatment response after TPO-RA discontinuation $[17,18,22,23]$. Červinek and colleagues [17] suggested that the TPO-RA dose needed to achieve a response may serve as a possible predictive marker. However, these preliminary results are based on small studies that were insufficiently powered to identify predictive factors. In one prospective trial [22], lower absolute immature platelet fraction value at discontinuation predicted sustained re- sponse. The other prospective study identified did not corroborate these findings [18].

Another remaining unmet need is the lack of standardized definitions for "successful off-treatment response" and "sustained off-treatment response." In some studies, these definitions were left to the treating physician's discretion or were not reported at all, possibly since platelet counts are specific to the individual. In 2009, an international working group defined complete response as platelet count $\geq 100,000 / \mu \mathrm{L}$ and absence of bleeding, whereas response was defined as a platelet count $\geq 30,000$ / $\mu \mathrm{L}$ and at least a twofold increase in the baseline count and absence of bleeding [25]. Successful or sustained offtreatment response was not defined by the international working group. Efforts should be undertaken to standardize these definitions.

\section{Conclusions}

This study confirms that TPO-RAs may be discontinued successfully in some patients with ITP. In the absence of established guidelines, our ITP expert panel reached consensus that hematologists may consider TPO-RA tapering and discontinuation after 6-12 months for patients with an adequate treatment response (platelet count $>50,000 / \mu \mathrm{L}$ in at least $75 \%$ of assessments in the preceding 6 months). Long-term prospective studies are warranted to determine whether this approach is indeed optimal, and predictive markers are needed to identify patients with ITP who may successfully stop TPO-RA treatment.

\section{Acknowledgements}

The authors would like to thank Elizabeth Kehler and Mark Silvey of the Adelphi Group for their support in the development and analysis of the surveys and consensus meeting. This study was funded by Novartis Pharmaceuticals. Writing and editorial support in the preparation of this manuscript was provided by Nicky Dekker, MD, PhD, of Excerpta Medica, funded by Novartis Pharmaceuticals.

\section{Statement of Ethics}

The paper is exempt from Ethics Committee approval since no patients participated in the study. All the participants have given their consent for being a part of the study. The authors have no ethical disclosures to declare. 


\section{Conflict of Interest Statement}

N. Cooper received speaking and ad board honoraria from Amgen and Novartis. Q.A. Hill received honoraria from Novartis for advisory work and speaking at educational events. J. Grainger received consultancy honoraria from Novartis, Alexion, Ono Pharma, Amgen, and GSK and travel grants from Novartis. J.P. Westwood received honoraria from Novartis for advisory work and speaking at educational events. C. Bradbury received speaker honoraria from BMS, Novartis, and Pfizer; honoraria for advisory work from Ablynx and Novartis; and support for conference attendance from Amgen, Bayer, and Novartis. D. Provan received honoraria and research support from Amgen and Novartis and consultancy honoraria from Amgen and Ono Pharma. J. Thachil received honoraria from Amgen and Novartis. N. Ramscar is a Novartis employee. A. Roy is a Novartis employee.

\section{Funding Sources}

This study was funded by Novartis Pharmaceuticals. The study sponsor (N. Ramscar and A. Roy) designed the study. Together with all other authors, N. Ramscar and A. Roy were involved in the collection, analysis, and interpretation of the data; in the writing of this manuscript; and in the decision to submit this paper for publication. All authors had full access to all the data in the study and had final responsibility for the decision to submit for publication. The opinions expressed are those of the clinicians, not of Novartis Pharmaceuticals.

\section{Author Contributions}

N. Ramscar and A. Roy designed the study. N. Cooper, Q.A. Hill, J. Grainger, J.P. Westwood, C. Bradbury, D. Provan, and J. Thachil participated in the expert panel. All authors participated in the data interpretation and directed development, review, and approval of this manuscript. All authors are fully responsible for all content and editorial decisions.

\section{References}

1 Neunert C, Terrell DR, Arnold DM, Buchanan G, Cines DB, Cooper N, et al. American society of hematology 2019 guidelines for immune thrombocytopenia. Blood Adv. 2019 Dec;3(23):3829-66.

2 Toltl LJ, Arnold DM. Pathophysiology and management of chronic immune thrombocytopenia: focusing on what matters. Br J Haematol. 2011 Jan;152(1):52-60.

3 Provan D, Arnold DM, Bussel JB, Chong BH, Cooper N, Gernsheimer T, et al. Updated international consensus report on the investigation and management of primary immune thrombocytopenia. Blood Adv. 2019 Nov; 3(22):3780-817.

4 Nurden AT, Viallard JF, Nurden P. New-generation drugs that stimulate platelet production in chronic immune thrombocytopenic purpura. Lancet. 2009 May;373(9674):15629.

5 Provan D, Stasi R, Newland AC, Blanchette VS, Bolton-Maggs P, Bussel JB, et al. International consensus report on the investigation and management of primary immune thrombocytopenia. Blood. 2010 Jan;115(2):168-86.

6 Bussel J, Saleh MN, Khelif A, Meddeb B, Salama A, Portella MSO, et al. Final safety and efficacy results from the EXTEND study: treatment with eltrombopag (EPAG) in adults with chronic immune thrombocytopenia (CITP). Haematologica. 2016;101(Suppl 1). abstract $S 517$

7 Trotter P, Hill QA. Immune thrombocytopenia: improving quality of life and patient outcomes. Patient Relat Outcome Meas. 2018 Nov;9:369-84.

Therapy Discontinuation in Immune Thrombocytopenia
8 Bussel JB, Kuter DJ, Pullarkat V, Lyons RM, Guo M, Nichol JL. Safety and efficacy of longterm treatment with romiplostim in thrombocytopenic patients with chronic ITP. Blood. 2009 Mar;113(10):2161-71.

9 Khellaf M, Michel M, Quittet P, Viallard JF, Alexis M, Roudot-Thoraval F, et al. Romiplostim safety and efficacy for immune thrombocytopenia in clinical practice: 2 -year results of 72 adults in a romiplostim compassionateuse program. Blood. 2011 Oct;118(16):433845.

10 Saleh MN, Bussel JB, Cheng G, Meyer O, Bailey CK, Arning M, et al. Safety and efficacy of eltrombopag for treatment of chronic immune thrombocytopenia: results of the longterm, open-label EXTEND study. Blood. 2013 Jan;121(3):537-45.

11 Rodeghiero F, Stasi R, Giagounidis A, Viallard JF, Godeau B, Pabinger I, et al. Long-term safety and tolerability of romiplostim in patients with primary immune thrombocytopenia: a pooled analysis of 13 clinical trials. Eur J Haematol. 2013 Nov;91(5):423-36.

12 Kuter DJ, Bussel JB, Lyons RM, Pullarkat V, Gernsheimer TB, Senecal FM, et al. Efficacy of romiplostim in patients with chronic immune thrombocytopenic purpura: a double-blind randomised controlled trial. Lancet. 2008 Feb;371(9610):395-403.

13 Bussel JB, Provan D, Shamsi T, Cheng G, Psaila B, Kovaleva L, et al. Effect of eltrombopag on platelet counts and bleeding during treatment of chronic idiopathic thrombocytopenic purpura: a randomised, doubleblind, placebo-controlled trial. Lancet. 2009 Feb;373(9664):641-8.
14 European Medicines Agency. Summary of Product Characteristics: Romiplostim. Available from: https://www.ema.europa.eu/documents/product-information/nplate-eparproduct-information_en.pdf. Accessed 2018 Dec 28.

15 European Medicines Agency. Summary of Product Characteristics: Eltrombopag. Available from: https://www.ema.europa.eu/documents/product-information/revolade-eparproduct-information_en.pdf. Accessed 2018 Dec 28.

16 Bussel JB, Kuter DJ, George JN, McMillan R, Aledort LM, Conklin GT, et al. AMG 531, a thrombopoiesis-stimulating protein, for chronic ITP. N Engl J Med. 2006 Oct;355(16): 1672-81.

17 Červinek L, Mayer J, Doubek M. Sustained remission of chronic immune thrombocytopenia after discontinuation of treatment with thrombopoietin-receptor agonists in adults. Int J Hematol. 2015 Jul;102(1):7-11.

18 Bussel JB, Mahmud SN, Brigstocke SL, Torneten SM. Tapering eltrombopag in patients with chronic ITP: how successful is this and in whom does it work? Blood. 2015;126(23): 1054. abstract 1054.

19 González-López TJ, Pascual C, ÁlvarezRomán MT, Fernández-Fuertes F, SánchezGonzález B, Caparrós I, et al. Successful discontinuation of eltrombopag after complete remission in patients with primary immune thrombocytopenia. Am J Hematol. 2015 Mar; 90(3):E40-3. 
20 González-López TJ, Sánchez-González B, Pascual C, Arefi M, de Cabo E, Alonso A, et al. Sustained response after discontinuation of short-and medium-term treatment with eltrombopag in patients with immune thrombocytopenia. Platelets. 2015;26(1):83-6.

21 Mahévas M, Fain O, Ebbo M, Roudot-Thoraval F, Limal N, Khellaf M, et al. The temporary use of thrombopoietin-receptor agonists may induce a prolonged remission in adult chronic immune thrombocytopenia. Results of a French observational study. Br J Haematol. 2014 Jun;165(6):865-9.

22 Leven E, Miller A, Boulad N, Haider A, Bussel JB. Successful discontinuation of eltrombopag treatment in patients with chronic ITP. Blood. 2012;120(21):1085. abstract 1085.

23 Ghadaki B, Nazi I, Kelton JG, Arnold DM. Sustained remissions of immune thrombocytopenia associated with the use of thrombopoietin receptor agonists. Transfusion. 2013 Nov;53(11):2807-12.
24 Stafkey-Mailey D, Roy A, Lokhandwala T, Yuan J, Landsman-Blumberg P, Siddiqui A, et al. Real-world treatment patterns among patients with immune thrombocytopenia (ITP) treated with eltrombopag in the US. Poster Presented at ISH 2018 Scientific Meeting; 2018 Sep 20-23; Beijing, China.

25 Rodeghiero F, Stasi R, Gernsheimer T, Michel M, Provan D, Arnold DM, et al. Standardization of terminology, definitions and outcome criteria in immune thrombocytopenic purpura of adults and children: report from an international working group. Blood. $2009 \mathrm{Mar}$; 113(11):2386-93.

26 Dillman DA, Smyth JD, Christian LM. Internet, phone, mail, and mixed-mode surveys: the tailored design method. 4th ed. Hoboken, NJ: Wiley; 2014.

27 British Healthcare Business Intelligence Association (BHBIA). BHBIA legal and ethical guidelines for healthcare market research. 2016. Available from: https://www.bhbia.org. uk/guidelines/legalandethicalguidelines. aspx. Accessed 2018 Dec 28.

28 Bussel JB, Saleh MN, Vasey SY, Mayer B, Arning M, Stone NL. Repeated short-term use of eltrombopag in patients with chronic immune thrombocytopenia (ITP). Br J Haematol. 2013 Feb;160(4):538-46.
29 Thachil J, Bagot C, Bradbury C, Cooper N, Lester W, Grainger JD, et al. A United Kingdom immune thrombocytopenia (ITP) forum review of practice: thrombopoietin receptor agonists. Br J Haematol. 2018 Feb; 180(4):591-4.

30 Rizvi H, Butler T, Calaminici M, Doobaree IU, Nandigam RC, Bennett D, et al. United Kingdom immune thrombocytopenia registry: retrospective evaluation of bone marrow fibrosis in adult patients with primary immune thrombocytopenia and correlation with clinical findings. Br J Haematol. 2015 May;169(4):590-4.

31 Newland A, Godeau B, Priego V, Viallard JF, López Fernández MF, Orejudos A, et al. Remission and platelet responses with romiplostim in primary immune thrombocytopenia: final results from a phase 2 study. Br J Haematol. 2016 Jan;172(2):262-73. 